\title{
Energy recovery of a rotary kiln system in a calcium oxide plant
}

\author{
M. Aldeib, A. Elalem \& S. Elgezawi \\ Department of Chemical Engineering, Faculty of Engineering, \\ University of AlFateh Tripoli, Libya
}

\begin{abstract}
The dominant source of calcium carbonate is limestone; the most common constituent of all rocks. It occurs in nature with clay, silica and other minerals, which may interfere in many applications. Synthetic calcium carbonate is produced on a large scale where a calcium chloride stream is treated with sodium or ammonium carbonate to produce a high grade of calcium carbonate. In turn, calcium carbonate is heated to $900-1000$ degree centigrade in a horizontal lime kiln to produce calcium oxide (burned lime). Calcium oxide is used extensively in cement, iron and steel industries due to the low cost of the material and its accepted chemical properties. In this study, composition of raw meal, ultimate analysis of the fuel, dust contents in the exhaust gases, losses in ignation (COI) and exhaust gas composition in the preheated suspension are calculated. The heat losses from kiln exhaust are minimized. A secondary shell on the kiln surface is also investigated. In this work mathematical models for the calculations of inside heat transfer on the rotary are used, and the total energy utilized by burning fuel oil in the process of calcium oxide production is also calculated. The heat losses for kiln exhaust gas, hot air from the cooler stock losses and radiation losses from kiln surface are also minimized. A secondary shell on the kiln surface is studied in the present study, where $4 \%$ of total energy input is saved. This energy saving would result in a considerable reduction of fuel consumption in the kiln system. The overall efficiency would be improved by $5 \%$.

Keywords: rotary kiln reactor, radiant heat transfer, coating, combustion.
\end{abstract}




\section{Introduction}

Radiant heat (mainly infra-red ray) is emitted from the burning flame at high temperature in a rotary kiln reactor, some fraction of which arrives at the surface of the rotating solids layer, and the other arrives at the inner refractory surface. The rest is absorbed in the combustion gas around the flame. For predicting radiant heat transfer, however, radiant heat transfer is simplified to apply to the complex mechanism of heat transfer in a rotary kiln, without losing significant fundamentals. Radiant heat absorbed in combustion gas around the flame is converted to thermal energy, which should be emitted as infra-red ray from the gas to the rotating solids and inner wall surface. Thus we can assume that all the radiant heat emitted from the flame arrives at the surface of the rotating solids and the inner wall surface.

\section{Mathematical modeling of inside heat transfer on a rotary kiln with radiant heat transfer from flame and combustion gas}

In the region where combustion takes place, radiant heat transfer from the burning flame is controlling, whereas convectional heat transfer is one order of magnitude less. For convenient application to practical design calculation, there are simplified models to represent the heat transfer mechanism in this region [1].

Radiant heat absorbed in combustion gas around the flame is converted to thermal energy, which should be emitted as infra-red rays from the gas to the rotating solids and inner wall surface. Thus we can assume that all the radiant heat emitted from the flame arrives at the surface of the rotating solids and the inner wall surface. The radiant heat transfer coefficient, $\mathrm{h}_{\mathrm{rg}}$, to two solid surfaces is calculated by, [1]

$$
\boldsymbol{h}_{\boldsymbol{r g}}=\frac{\left\langle\boldsymbol{d}_{t i} / \boldsymbol{d}_{\boldsymbol{F}}\right\rangle(\varepsilon \boldsymbol{F} \varepsilon m)(4.88)\left[\left(\frac{\mathrm{TF}+273}{100}\right)^{4}-\left(\frac{T *+273}{100}\right)^{4}\right]}{\boldsymbol{T}_{\boldsymbol{F}^{-T^{*}}}}
$$

where $d_{\mathrm{f}}$ is the outer diameter of the flame, $\varepsilon_{\mathrm{f}}$ is the emissivity of the flame, $\varepsilon_{\mathrm{m}}$ is the average emissivity of the solids layer surface and the inner wall surface, and $\mathrm{T}^{*}$ is the average temperature of the above two surfaces. The emissivity of the luminous flame was measured very precisely by members of an international committee. The average diameter of flame $d_{\mathrm{f}}$ depends strongly on the hydrodynamic feature of turbulent diffusion. By visual observation of the flame in a practical rotary kiln, in which a burner is operated under similar flow conditions to the one planned, we can estimate the approximate value of $\mathrm{d}_{\mathrm{f}} / \mathrm{d}_{\mathrm{ti}}$

The average temperature $T *$ is calculated using the following equation:

$$
\boldsymbol{T}^{*{ }^{*}{ }^{T} C}(\mathbf{1}-\boldsymbol{x})_{T_{H}}
$$




\section{Radiant heat transfer from inner wall surface to rotating solids layer}

Radiant heat emitted from the wall surface per unit length of the reactor is given by [1]

$$
\left\langle\pi d_{t i}\right\rangle\langle 1-x\rangle_{\mathcal{E}_{\mathcal{H}}}(4.88)\left(\frac{T_{H}+273}{100}\right)^{4}
$$

The geometrical view (angle) factor from the inner surface $\boldsymbol{\pi} \boldsymbol{d}_{\mathrm{ti}}(\mathbf{1}-\chi)$ to the rotating layer of solids is represented by $F_{\mathrm{HC}}$.

$$
\pi d_{t i}(1-x) F_{H C}=\pi d_{i t}{ }^{\mathrm{xF}} \mathrm{CH}
$$

Since $F_{\mathrm{CH}}=1$, we have $F_{\mathrm{HC}}=\chi / 1-\chi$.

Radiant heat, emitted from the inner surface, is mainly infrared rays. When it passes through the flame and combustion gas, some part of the infrared ray is absorbed by them.

Let us take $\varepsilon_{\mathrm{g}}{ }^{*}$ to be the average value of emissivity for the flame and combustion gas. Thus, the rate of radiant heat transfer from the inner wall surface to the rotating solids layer is calculated approximately with Eq. (5), in the case where $\varepsilon_{\mathrm{H}}$ and $\varepsilon_{\mathrm{C}}$ are close to unity.

$$
\left[\left\langle\pi d_{t i}\right\rangle(1-x)\left(\varepsilon_{\mathcal{H}} \varepsilon_{C}\right)\left(\frac{T_{H}+273}{100}\right)^{4}-\left(\frac{T_{H}+273}{100}\right)^{4}\right] \mathbf{F}_{\left.\mathrm{HC}^{\langle 1-\varepsilon * \mathrm{~g}}\right\rangle}
$$

Define the radiant heat transfer coefficient from the hot inner wall to the layer of solids by $\left(h_{\mathrm{rs}}\right) \mathrm{HC}$, on the basis of the surface area of the inner wall.

$$
\pi d_{t i} X\left\langle h_{r s}\right\rangle H C\left\langle\mathrm{~T}_{\mathrm{H}}-\mathrm{T}_{\mathrm{C}}\right\rangle
$$

Combination of Eqs. (5) and 6) leads to the following equation

$$
h_{r s} \mathbf{H C}=\varepsilon_{\mathrm{H}}\left(1-\varepsilon *_{g}\right) \varepsilon_{C}\langle 4.88\rangle\left[\left(\frac{T_{H}+273}{100}\right)^{4}-\left(\frac{T_{H}+273}{100}\right)^{4}\right]
$$

\section{Heat transfer coefficient by direct contacting of solids from the hot wall surface}

In a rotary kiln, solids are heated by direct contact with the hot wall surface. The inner wall surface functions as a kind of regenerator, changing the surface temperature periodically during the rotation. Theoretical calculation reveals that the amplitude in the periodical change of surface temperature is not too much, as long as the rotation is larger than 3 r.p.m. In this section, let us take the time averaged temperature of the wall. For a packet of solids, which suddenly contact the hot surface and then leave it after residing there for a time $t$, the following equation calculate the time averaged value of the heat transfer coefficient due to the above contact, on the basis of contacting surface area. 


$$
\left(h_{P}\right) H C=h_{\text {packet }}=1.13\left[\frac{\mathrm{K}_{\mathrm{K}}{ }_{\mathrm{P}}}{t}\right]
$$

where $\mathrm{k}_{\mathrm{e}}$ is the effective thermal conductivity of a packet of solids, $\bar{\rho}$ is the bulk density, and $C_{\mathrm{s}}$ is the specific heat of solid.

Introduce the following substitution:

$$
t=X / N
$$

Substitution of Eq. (9) in Eq. (8) gives

$$
\left(h_{p}\right) \mathrm{HC}=\mathrm{h}_{\text {packet }}=1.13\left[\frac{K_{e} \bar{\rho} C_{s} N}{\chi}\right]^{0.5}
$$

The temperature of the inner wall surface $T_{\mathrm{H}}$ is determined by a given value of the flame temperature $T_{\mathrm{f}}$. On the basis of unit length, using the following equation:

$$
\left(\boldsymbol{\pi} \boldsymbol{d}_{t i}\right)(\mathbf{1}-\chi) \mathbf{h}_{\mathrm{rg}}\left(\mathbf{T}_{\mathrm{F}}-\mathbf{T}_{\mathrm{H}}\right)
$$

Heat transfer from the inner wall to the rotating solids by direct contact can be calculated using Eq. (12)

$$
\left(\pi d_{t i}\right)(1-\chi) h_{\mathrm{rg}}\left(\mathrm{T}_{\mathrm{F}}-\mathrm{T}_{\mathrm{H}}\right)
$$

Heat loss to outside with coating is estimated from the following equation:

$$
Q^{\prime \prime}=\frac{T_{H}-T_{W}}{\frac{\ln (r 2 / r 1)}{k_{\text {coating }}}+\frac{\ln (r 3 / r 2)}{k_{\text {bricks }}}+\frac{\ln (r 4 / r 3)}{k_{\text {shell }}}} \ldots \ldots \ldots
$$

\section{Mathematical modeling of inside heat transfer on a rotary kiln without coating}

The same procedure done: from equation (1) to equation (12) but eliminate the first term in the denominator from equation (13).

\subsection{Investigation of the mathematical model:}

\section{Known data}

$\mathrm{T}_{\mathrm{c}}=950^{\circ} \mathrm{C}$,

$$
\varepsilon_{c}=0.84, \varepsilon_{m}=0.8, \varepsilon_{f}=0.7
$$

$\mathrm{d}_{\mathrm{ti}}=4.2 \mathrm{~m}$ (with coating), and equal $4.35 \mathrm{~m}$ (without coating), $\mathrm{d}_{\mathrm{f}}=1.4 \mathrm{~m}$.

Flame temperature $\left(T_{f}\right)$ range in cement industry from 1200 to $2000^{\circ} \mathrm{C}$. 


\section{Results from Program}

The results calculated are shown in the following tables:

\section{With coating}

Table 1 presents both internal and external temperatures of rotary kiln for the burning zone; they are functions of flame temperature, and increase with the flame temperature. Also, the heat loses are increased, due to increase in the difference of temperature between the inside (flame) and outside (environment) temperatures.

Table 1: Prediction of inner and outer shell surface temperatures with coating.

\begin{tabular}{c|ccccc|}
$\mathrm{T}_{\mathrm{f}}\left({ }^{\circ} \mathrm{C}\right)$ & 1200 & 1400 & 1600 & 1800 & 2000 \\
\hline $\mathrm{T}_{\mathrm{H}}\left({ }^{\circ} \mathrm{C}\right)$ & 1029.8 & 1133.6 & 1237.4 & 1341.2 & 1445 \\
$\mathrm{~T}_{\mathrm{W}}\left({ }^{\mathrm{o}} \mathrm{C}\right)$ & 267.85 & 297.85 & 327.85 & 357.85 & 387.85 \\
$\mathrm{Hrg}$ & 98.66 & 133.06 & 174.9 & 224.95 & 283.94 \\
$\mathrm{Hrs}$ & 158.68 & 179.76 & 203.14 & 228.95 & 257.35 \\
$\mathrm{Hp}$ & 561.89 & 561.89 & 561.89 & 561.89 & 561.89 \\
$\mathrm{Q}_{\text {losses }}$ & 5990.41 & 6570.621 & 7150.83 & 7731.04 & 8311.25 \\
$\left(\mathrm{kcal} / \mathrm{m}^{2} . \mathrm{hr}\right)$ & & & & & \\
\cline { 3 - 5 } & & & & &
\end{tabular}

These behaviors are clarified in table 1 whereas increasing the flame temperature with the industrial range (from 1200 to $2000^{\circ} \mathrm{C}$ ) note that, both internal and external wall surface temperatures are increased respectively. Table 2 presents both internal and external temperatures of rotary kiln for the burning zone; are function of flame temperature, and increasing with increase the flame temperature. Also, the heat loses increase, due to increase in the difference of temperatures between the inside (flame) and outside (environment) temperatures. The optimum external wall surface temperature in industrial processes ranged (from 250 to $340^{\circ} \mathrm{C}$ ), Note that in Table 2, $\mathrm{T}_{\mathrm{w}}$ reaches up to $379^{\circ} \mathrm{C}$ when the flame temperature greater than $1580^{\circ} \mathrm{C}$. That will lead to many

Table 2: $\quad$ Predicted temperatures of inner wall surface and outer shell surface without coating.

\begin{tabular}{c|ccccc}
$\mathrm{T}_{\mathrm{f}}\left({ }^{\circ} \mathrm{C}\right)$ & 1200 & 1400 & 1600 & 1800 & 2000 \\
\hline $\begin{array}{c}\mathrm{T}_{\mathrm{H}}\left({ }^{\circ} \mathrm{C}\right) \\
\mathrm{T}_{\mathrm{W}}\left({ }^{\circ} \mathrm{C}\right)\end{array}$ & 1029.8 & 1133.6 & 1237.4 & 1341.2 & 1445 \\
$\mathrm{Hrg}$ & 87.097 & 117.64 & 154.4 & 198.58 & 283.94 \\
$\mathrm{Hrs}$ & 158.68 & 179.76 & 238.14 & 228.95 & 257.35 \\
$\mathrm{Hp}$ & 561.89 & 561.89 & 561.89 & 561.89 & 561.89 \\
$\begin{array}{c}\text { Q } \\
\left(\mathrm{kcal} / \mathrm{m}^{2} . \mathrm{hr}\right.\end{array}$ & 5921.224 & 6463.698 & 7242.03 & 8271.945 & 8802.627 \\
\cline { 3 - 6 }
\end{tabular}




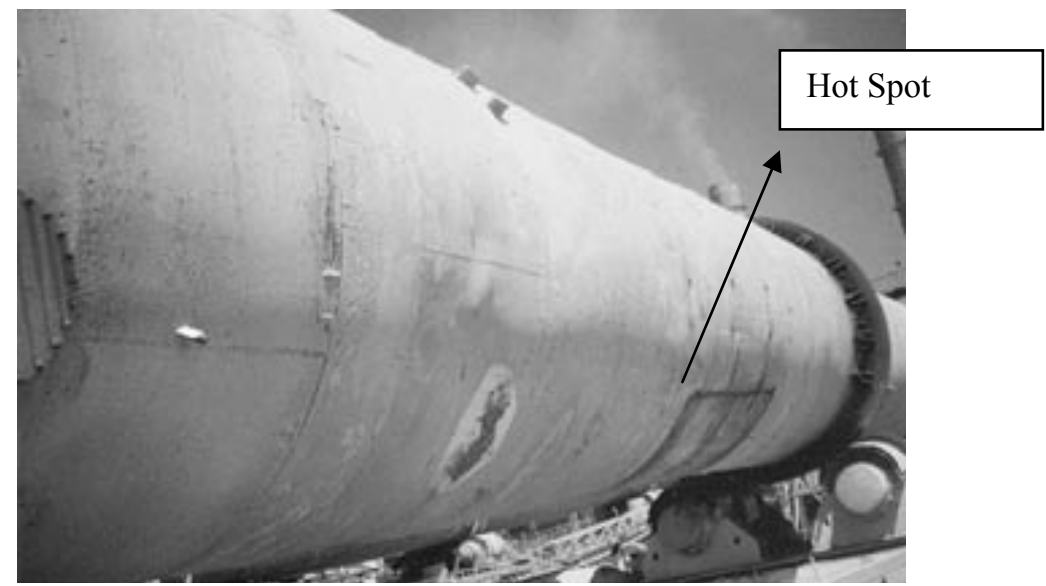

Figure 1: Hot spot formation on the rotary kiln shell surface.

troubles in the rotary kiln in this case the red spot (hot spot as shown in Figure 1 through the rotary kiln will occur, in which the coating will start to collapse that leading to decrease in the thermal resistance that leads to increase in the external wall surface temperature $\left(\mathrm{T}_{\mathrm{w}}\right)$ reaching up to $450^{\circ} \mathrm{C}$ which is known as red spots.

Table 3 shows that the internal wall surface temperature predicted by model is satisfied with practical data obtained from industrial process with acceptable deviation.

Table 3: Prediction and practical temperatures of inner wall surface and outer shell surface.

$\begin{array}{llllll}\mathrm{T}_{\mathrm{f}}\left({ }^{\circ} \mathrm{C}\right) & 1200 & 1400 & 1600 & 1800 & 2000\end{array}$

\begin{tabular}{|c|ccccc|}
\hline $\begin{array}{c}\mathrm{T}_{\mathrm{H}}\left({ }^{\circ} \mathrm{C}\right) \\
\text { (actual) }\end{array}$ & 1029.8 & 1133.6 & 1237.4 & 1341.2 & 1445 \\
$\begin{array}{c}\mathrm{T}_{\mathrm{H}}\left({ }^{\circ} \mathrm{C}\right) \\
(\text { predicted })\end{array}$ & 1021 & 1120 & 1249 & 1410 & 1501 \\
$\mathrm{~T}_{\mathrm{W}}\left({ }^{\circ} \mathrm{C}\right)$ & 267.85 & 297.85 & 327.85 & 357.85 & 387.85 \\
$\mathrm{Hrg}$ & 98.66 & 133.06 & 174.9 & 224.95 & 283.94 \\
$\mathrm{Hrs}$ & 158.68 & 179.76 & 203.14 & 228.95 & 257.35 \\
$\mathrm{Hp}$ & 561.89 & 561.89 & 561.89 & 561.89 & 561.89 \\
$\begin{array}{c}\mathrm{Q}_{\text {losses }} \\
\left(\mathrm{kcal} / \mathrm{m}^{2} . \mathrm{hr}\right)\end{array}$ & 5990.41 & 6570.621 & 7150.83 & 7731.04 & 8311.25 \\
$\begin{array}{c}\mathrm{Q}_{\text {losses }} \\
\left(\mathrm{kcal} / \mathrm{m}^{2} . \mathrm{hr}\right)\end{array}$ & 5921.224 & 6463.698 & 7242.03 & 8271.945 & 8743.66 \\
\cline { 2 - 6 }
\end{tabular}




\section{Conclusion}

A detailed energy audit analysis, which can be directly applied to any dry kiln system has been made in this study. The distribution of the input heat energy to the system components showed good agreement between the total input and output energy and give significant insight about the reasons for the low overall system efficiency. According to the results obtained, the system efficiency is $50 \%$. The major heat loss sources have been determined as kiln exhaust with $20 \%$. Cooler exhaust heat loss is calculated at $5 \%$ of total input. The combined radiative and convective heat transfer from kiln surface is at $4 \%$ of total input. The simulation done on the process showed that the predicted external wall surface temperature is ranged from 267 to 327 degree centigrade to avoid hot spot formations on the rotary kiln surface.

\section{References}

[1] D. Kunii and T. Chisaki, Rotary Reactor Engineering, First edition, Jordan Hill, 2008

[2] Deliang Shi, Watson Vargas, J. Mc Carthy, Heat Transfer in Rotary Kilns with Interstitial gases, Chemical Engineering Science 63, 2008 